\title{
LÍNGUA: O “DIFERENTE” NO INTERIOR DO MESMO NA GRAMÁTICA 1
}

Marcia Ione Surdi

Mestranda (UFSM); Professora da Unochapecó, SC.

Dr. ${ }^{\text {a Verli Petri }}$

UFSM -RS.

RESUMO: Para a elaboração deste trabalho, partimos da possibilidade de o "diferente" fazer parte do mesmo, da heterogeneidade ser constitutiva daquilo que aparentemente é da ordem do homogêneo. Nossa proposta é a de explorar as possibilidades de sentidos sobre a gramática, dando especial ênfase à gramática normativa, enquanto objeto linguístico-discursivo, mobilizando o aparato teóricometodológico da Análise de Discurso de Linha Francesa em diálogo com a História das Ideias Linguísticas. As noções que merecem destaque em nossa abordagem são: gramatização e gramática, segundo Orlandi (2007); a noção de designação, conforme Guimarães (1995); bem como as noções de normal e anormal, a partir de Canguilhem (2002).

PALAVRAS-CHAVE: língua; gramática normativa; heterogêneo; homogêneo.

ABSTRACT: In order to develop this research, it was necessary to start by the possibility of the "different" making part of it, the heterogeneity being part of what apparently belongs to homogeneous order. Our proposal is to explore the possibilities of meaning on the grammar, with special emphasis on the normative grammar, as object-language discourse, involving the theoretical and methodological apparatus of the Discourse Analysis according to French conceptions in dialogue with the History of Linguistic Ideas. The notions that deserve emphasis in our approach is grammar, following Orlandi (2007); the notion of designation, according to Guimarães (1995); as well as the notions of normal and abnormal, according to Canguilhem (2002).

KEYWORDS: language; normative grammar; heterogeneous; homogeneous.

\section{Introdução}

A ideia de que a língua não se constitui como um objeto homogêneo e sim como um conjunto de elementos em movimento, em que tem lugar a diversidade/variedade/heterogeneidade, "o diferente", não causa maior estranhamento àqueles que tomam a língua em sua materialidade histórica e social como objeto de estudo e análise.

Para fazer referência ao diverso, ao heterogêneo, ao variado, ao mutável, entre outras possibilidades, utilizaremos o termo "diferente" para agrupar tais elementos, numa tentativa de conter sentidos múltiplos em uma palavra, considerando, assim, o efeito de plasticidade que as palavras carregam. Nessa direção, partimos do pressuposto de que há possibilidades de o "diferente" fazer parte do mesmo, de a heterogeneidade ser constitutiva daquilo que aparentemente é da ordem do homogêneo: a gramática normativa. 
Tomamos por base teórica a Análise de Discurso de linha francesa, fundada por Michel Pêcheux, e atualmente desenvolvida por Eni Orlandi (e outros) no Brasil, estabelecendo diálogo com pressupostos da área de História das Ideias Linguísticas. No ensejo de explorar as possibilidades de sentidos sobre a gramática, dando especial ênfase à gramática normativa, destacamos as principais noções abordadas neste artigo: as noções de gramática, segundo Orlandi (2007); a noção de designação, conforme Guimarães (1995), bem como as noções de normal e anormal, a partir de Canguilhem (2002).

A partir da discussão teórica apresentamos elementos advindos de nossas análises, tendo como objeto a Gramática Normativa da Língua Portuguesa (31aㅡ edição), de Carlos Henrique da Rocha Lima, publicada em 1991 pela editora José Olympio. O presente artigo traz inicialmente reflexões acerca do instrumento linguístico gramática, a partir das quais é possível explorar diferentes possibilidades de sentidos vinculadas à definição, propriamente dita, do que vem a ser gramática, suas diferentes acepções e seu específico funcionamento. Nesta esteira são elencados elementos de análise, revelando-se, então, os espaços de "emergência" do diferente no interior do mesmo, enquanto constitutivo da gramática.

\section{Algumas considerações sobre gramática}

Atualmente a designação $\underline{2}$ "gramática" tem sido amplamente utilizada e os sentidos que se produzem acompanham a variedade de situações à qual ela se mostra adequada. Falar de gramática já não é mais privilégio dos estudiosos da linguagem, stricto sensu, tendo em vista que as relações de sinonímia disseminaram novos espaços para o funcionamento desta designação. A história da humanidade nos mostra que ela remonta à Grécia Antiga e que se revela inicialmente como: conjunto de regras individuais. Tal definição é ainda reproduzida, mas já não é a única nem mais ressoa da mesma maneira. De fato, observamos que o "diferente" está movimentando a noção de gramática, conforme explicita-se nos três exemplos que selecionamos para o início de nossa reflexão.

Paolo Virno, por exemplo, publica no início do século XX, sua "Gramática da Multidão" desalojando a noção de reparar/consertar os modos de subjetivação contemporâneos, buscando trabalhar com o propósito de reformular o que está dado como oposição: as relações entre o Uno e o Muitos, destacando que "podese conceber um Uno que, longe de ser um porquê concludente, seja a base que autoriza a diferenciação, que consente a existência político-social dos muitos enquanto muitos". Nesse caso, então, podemos observar que o estudioso joga com a relação de tensão que existe entre o uno e o muitos, entre o mesmo e o diferente, fazendo ressoar de outro modo os ecos do que seria uma "gramática". 
Temos também a "Gramática do Tempo", de Boaventura de Souza Santos, espaço privilegiado de discussão dos modos de gestão do crescente universalismo da desigualdade e da exclusão na cultura política ocidental, apresentando sua crítica aos contornos questionáveis que ganha a democracia atualmente. Então, a gramática emerge, e agora ela é "do tempo", acionando outras possibilidades de sentidos, ressoando de outra forma.

E, temos, ainda, a "Gramática do Corpo". Essa gramática, bastante discutida na área de Psicologia, é explorada nessa relação completude/incompletude que, de certa forma, também nos move na investigação. Enfatizamos, especialmente, o trabalho de Andrea Menezes Masagão (USP), intitulado "A gramática do corpo e a escrita do nome" $\underline{3}$, no qual destaca-se a noção de "gramática pulsional" que é "híbrida", sendo que o sonho "é uma realização de desejo e sua gramática aponta para uma letra híbrida que diz dos orifícios do corpo."

Esta rápida exemplificação das diferentes formas de aparecimento/reaparecimento da designação gramática, na contemporaneidade, explicita a força de um movimento que não se restringe aos estudos da linguagem - mas que os leva em consideração - e que coaduna o mesmo e o diferente como constitutivos e não como representantes de um par opositivo incontornável como já foram um dia os pares língua/fala, gramatical/agramatical, certo/errado. O mesmo, o uno, o perfeito é constituído na relação com o diferente, com o muitos, com o imperfeito. Em nosso entender, o que reúne diferentes trabalhos acerca de uma "gramática" é a possibilidade de olhar e ver que a heterogeneidade é constitutiva, seja do "eu", seja da língua, seja da sociedade. Isso interessa para quem investiga a gramática do ponto de vista da língua em relação com a história, do discurso em relação às possibilidades de sentidos.

\section{A gramática: instrumento linguístico}

Nosso objeto de estudo, neste texto, é a Gramática Normativa, de Rocha Lima, tomada enquanto instrumento linguístico, enquanto materialidade discursiva passível de ser analisada quando se leva em conta que "conhecer uma língua não é apenas conhecer as formas engendradas pela gramática, mas também o valor social atribuído a elas." (ORLANDI, 1987, p. 102). Mas partir desta perspectiva e com vistas neste objeto específico traz à baila algumas implicações teórico-metodológicas das quais destacamos as seguintes:

a gramática é, antes de tudo, resultado de um longo e complexo processo de gramatização da língua portuguesa do Brasil;

trata-se de um instrumento linguístico que revela traços da história de uma língua herdada de Portugal; plena em memória, com suas lacunas e 
saturações;

há que se considerar que, historicamente, a gramática funciona para a consolidação das políticas linguísticas desenvolvidas no país;

a gramática é um objeto da cultura material; um livro que regula o que se pode e se deve dizer em "bom" português; lugar que contém o saber sobre a língua; enfim, um manual de bem falar e bem escrever;

e, em última instância, ferramenta política que funciona na duplicidade do movimento de apagamento da diversidade étnico-linguageira do Brasil e a institucionalização de uma língua-nação una e forte.

Destacadas as implicações que consideramos imbricadas em toda nossa discussão, selecionamos algumas das noções correntes em nosso meio acadêmico, trazendo Fávero, Mattoso Câmara e Orlandi, conforme segue.

Fávero (2006) argumenta que a gramática vem descrevendo, comparando e prescrevendo normas para o "bem falar e escrever", numa função normativa. Assim, podemos dizer que a gramática normativa, especialmente, estabelece parâmetros para definir se a utilização da língua está correta ou não. É ao prescrever normas que ela apresenta a estrutura, a "única" estrutura possível, em se tratando de língua padrão.

Mattoso Camara Júnior (1986, p. 98) define ainda a disciplina gramatical o "conjunto de prescrições que se estabelecem para impor uma norma linguística no uso falado e escrito", no que diz respeito às suas formas, tipos de frase, vocabulário, pronúncia e ortografia. Na língua escrita, a disciplina gramatical baseia-se no uso literário, ou seja, no uso dos grandes escritores de determinada época. Isso acaba determinando, em muitos casos, os modos de organização dos livros didáticos de ensino de língua e, consequentemente, as formas de apresentação das aulas de língua portuguesa nas escolas.

De acordo com o Dicionário de Linguística e Gramática, de Mattoso Camara Júnior (1986, p. 177), a palavra norma é apresentada como o "conjunto de hábitos vigentes no lugar ou na classe social mais prestigiosa no País". A norma é contrariada pela variabilidade linguística intrínseca, que se verifica de um lugar para outro, de uma classe social para outra e de um indivíduo para outro. Segundo o autor, do ponto de vista da norma, a variabilidade que a contraria constitui o erro, que é de três espécies: o regionalismo, o vulgarismo e erros individuais, correspondentes ao idioleto. Para o autor, tais erros atuam contra a norma e tendem a enfraquecê-la ou modificá-la, principalmente quando na estrutura social se debilita o prestígio do lugar e da classe que representa. Portanto, a norma é uma força conservadora na linguagem e, em muitas sociedades altamente evoluídas, a norma se torna operante e agressiva, por meio do ensino escolar e da organização de uma disciplina gramatical.

Assim, entendemos que refletir sobre gramática, em suas relações com o mesmo e com o diferente, pressupõe a tomada deste instrumento também em 
relação com a história e com o social, o que ressalta o papel político deste instrumento na formação/consolidação de uma nação pela e na língua. Nossa perspectiva teórico metodológica coaduna com a noção proposta por Orlandi (2007, p. 54), pois entendermos que nela convergem as implicações mencionadas. Então

[...] as gramáticas são objetos históricos, são instrumentos linguísticos e constituem um lugar de construção e representação da unidade e da identidade (Língua/Nação/Estado), através do conhecimento, em uma tentativa de salvaguardar a língua.

Nessa perspectiva, a gramática de uma língua constitui-se em um projeto que visa a dar unicidade e identidade a um conjunto heterogêneo, privilegiando, pelo menos, dois aspectos: o sujeito falante e o Estado-Nação que o representa e que é representado nele. Individualiza-se o país, seu saber, sua língua, seu sujeito político social e suas instituições. Nesta pretensa unicidade não caberia o diferente, o anormal, o "errado".

\section{O normal e o anormal na e da língua: uma questão de gramática}

Pensar a questão do "diferente", neste trabalho, põem-se em relação, ainda, as noções de normal, normatividade e anormal. Centraremos nossa exposição em torno do nome de Georges Canguilhem porque é pela história das ideias desse autor, segundo Petri (s.d.) $\underline{4}$, que depreendemos o quão profícua é sua contribuição para que se institua uma nova forma de se pensar o fazer científico e a história da ciência, propriamente dita, tal como a concebemos até hoje. Merece destaque a sua trajetória teórico-filosófica empreendida a partir de 1943, época em que conclui sua tese sobre o normal e o patológico. Trata-se de um filósofo que dialoga com seus contemporâneos e reflete bastante acerca das questões da linguagem, dentre os quais está Michel Pêcheux.

Conforme Canguilhem (2002), o conceito de normal é reduzido a um conceito qualitativo e polivalente, estético e moral. O termo normal advém de norma, regra, ou seja, o que é conforme à regra, regular, como um esquadro, aquilo que não pende nem para a esquerda nem para a direita, portanto, o que se conserva em um justo meio-termo. "Uma norma, uma regra, é aquilo que serve para retificar, pôr de pé, endireitar" (p. 211). Então, “Uma norma se propõe como um modo possível de unificar um diverso, de reabsorver uma diferença, de resolver uma desavença" (p. 212).

Quanto à normatividade, Canguilhem (2002, p. 96) explicita que “[...] entende-se por normativo qualquer julgamento que aprecie ou qualifique um fato em relação a uma norma, mas essa forma de julgamento está subordinada, no fundo, àquele que institui as normas. No pleno sentido da palavra, normativo é o que institui as normas." 
O termo anormal, para o autor, implica referência a um valor, é um termo apreciativo, normativo. "O anormal, enquanto a-normal, é posterior à definição do normal, é a negação lógica deste” (p.216). Portanto, o anormal é o desregrado, irregular, fora de um esquadro, é o que está fora da norma, é o que pende para a direita e/ou para a esquerda. É um modo de conceber o diferente como constitutivo do mesmo, pois só se identifica uma irregularidade estabelecendo relações com aquilo que regula, regra. É nesta direção que caminha nossa reflexão, tentando mostrar que a regulação e a normatividade não dá conta de partes do todo que estão na esfera do diferente, do anormal que constitui o normal, enfim, isso também se revela no espaço da gramática.

\section{Um possível movimento de análise}

Nossa reflexão acerca da gramática, do mesmo e do diferente, do normal e do anormal, direciona nosso olhar para o objeto de estudo: a Gramática Normativa que nos desafia, e precisamos investir em direção à análise e reflexão.

Consideramos pertinente fazer algumas observações iniciais para justificar a escolha do objeto de análise, de onde selecionamos Sequências Discursivas (SDs) que constituem o nosso corpus de análise. Selecionamos um instrumento linguístico designado como gramática normativa, ou seja, "uma disciplina, didática por excelência, que tem por finalidade codificar 'o uso idiomático', dele induzindo, por classificação e sistematização, as normas que, em determinada época, representam o ideal da expressão correta", assim definida por Rocha Lima (1991, p. 7). A primeira edição dessa gramática data de 1957 e hoje já se encontra com mais de quarenta edições publicadas, sendo que somente em 1991, na $31^{\text {a }}$ edição a referida gramática sofreu alterações, ou como o próprio autor diz foi "retocada e enriquecida".

Assim, a partir da $31^{\underline{a}}$ edição da Gramática Normativa da Língua Portuguesa percebemos que ela não é mais a "mesma gramática", também não chamaremos de "outra gramática", sim diremos que ela está "diferente", e por força do destino, ou incômodo, é a diferença que nos interessa. Partindo desta perspectiva, concordamos com Courtine (2006) que já dizia que é preciso encontrar textos que incomodem. A proposta normativa, homogênea, linear do objeto de análise nos incomodou. Esse incômodo apresenta uma singularidade de olhar sobre o objeto de estudo. Nossa investigação segue pistas que sinalizam a presença do diferente no interior do mesmo, buscando desconstruir pares opositivos e reformular as questões que perduram acerca da constituição, instituição e funcionamento da gramática.

Para isso, foram selecionadas sequências discursivas, do texto introdutório d a Gramática Normativa da Língua Portuguesa, que apresentam termos e 
definições que remetem aos sentidos de "norma-mesmo" (unidade, homogeneidade) e "anormal-diferente" (diversidade, heterogeneidade).

\begin{tabular}{|c|c|}
\hline $\begin{array}{c}\text { Em relação à noção "norma- } \\
\text { mesmo" } \\
\text { (unidade, homogeneidade) } \\
\text { destacamos: }\end{array}$ & $\begin{array}{c}\text { Em relação à noção de "anormal- } \\
\text { diferente" (diversidade, } \\
\text { heterogeneidade) destacamos: }\end{array}$ \\
\hline $\begin{array}{l}\text { SD1a - as normas que, em } \\
\text { determinada época, representam o } \\
\text { ideal da expressão correta }\end{array}$ & $\begin{array}{l}\text { SD1b - dentro da ampla coesão da } \\
\text { língua cabem vários aspectos que se } \\
\text { influem }\end{array}$ \\
\hline $\begin{array}{l}\text { SD2a - Fundamentam-se as regras } \\
\text { da gramática normativa nas obras } \\
\text { d o s grandes escritores, em cuja } \\
\text { linguagem, as classes ilustradas } \\
\text { põem o seu ideal de perfeição, } \\
\text { porque nela é que se espelha o que } \\
\text { o uso idiomático estabilizou e } \\
\text { consagrou }\end{array}$ & $\begin{array}{l}\text { SD2b - linguagem mutilada } \\
\text { SD2c - uso de termos chulos, } \\
\text { gravosos, pouco limpos } \\
\text { SD2d - Calão é a língua especial das } \\
\text { classes que vivem à margem da } \\
\text { sociedade }\end{array}$ \\
\hline $\begin{array}{l}\text { SD3a - (a gramática normativa) } \\
\text { código de bem falar e escrever }\end{array}$ & $\begin{array}{l}\text { SD3b - Língua especial dos } \\
\text { delinquentes }\end{array}$ \\
\hline $\begin{array}{l}\text { SD4a - àqueles escritos de } \\
\text { linguagem } \\
\text { dentro dos padrões da norma culta }\end{array}$ & $\begin{array}{l}\text { SD4b - Gíria é a língua especial de } \\
\text { uma profissão ou } \begin{array}{l}\text { ofício, } \\
\text { caracterizada por } \\
\text { idiomática deficiente }\end{array}\end{array}$ \\
\hline $\begin{array}{l}\text { SD5a - a unificação, força coercitiva, } \\
\text { disciplinante, conservadora }\end{array}$ & $\begin{array}{l}\text { SD5b - a diferenciação, força } \\
\text { natural, espontânea, desagregadora }\end{array}$ \\
\hline $\begin{array}{l}\text { SD6a - Ao assenhorar-se dos } \\
\text { recursos da língua, cada indivíduo, } \\
\text { culto o u ignorante, a executa à sua } \\
\text { maneira... }\end{array}$ & $\begin{array}{l}\text { SD6b - Ao assenhorar-se dos } \\
\text { recursos da língua, cada indivíduo, } \\
\text { culto ou ignorante, a executa à sua } \\
\text { maneira... }\end{array}$ \\
\hline
\end{tabular}

As Sds acompanhadas da letra $a$ nos remetem ao normativo/normal, já as Sds acompanhadas da letra $b$ nos remetem à heterogeneidade/anormal.

Iniciando nossa análise, podemos observar que o sentido de norma é constituído pelo funcionamento discursivo em que entram em jogo os sentidos de: expressão correta, classes ilustradas, ideal de perfeição, uso consagrado, bem falar e escrever e padrões da norma culta. O segundo termo predica e determina o sentido do primeiro termo, ou seja, não é qualquer expressão, é a expressão correta; não é qualquer padrão, é o padrão da norma culta.

O sentido de "diferente" é constituído pelos sentidos de: língua especial, língua especial dos delinquentes, educação idiomática deficiente. Nesses casos, o segundo termo também predica e determina o sentido do primeiro termo, assim, não é qualquer língua, é, sim, a língua especial dos delinquentes. Assim, 
podemos perceber que ao predicar sobre a língua, o sujeito-autor da gramática marca qual é a sua posição em relação à concepção de língua e do papel do "diferente": a língua normal é a que corresponde ao padrão culto, o que fugir disso, é deficiente. No entanto, o diferente aparece discursivizado, é lugar de desconforto, mas não fica de fora; impossível não falar dele, mesmo que seja para negá-lo, desqualificá-lo numa relação comparativa com a variedade culta da língua.

Partindo das noções de normal e anormal de Canguilhem (2002), podemos listar alguns pares opositivos, retirados das sequências discursivas apresentadas na tabela anterior:

\begin{tabular}{|c|c|}
\hline Normal $=$ Norma $=$ Correto & $\begin{array}{c}\text { Anormal }=\text { "Diferente" } \\
\text { Incorreto }\end{array}$ \\
\hline unificação & diferenciação \\
\hline força coercitiva & força natural \\
\hline disciplinante & espontânea \\
\hline conservadora & desagregadora \\
\hline culto & ignorante \\
\hline código de bem falar e escrever & língua especial dos delinquentes \\
\hline padrões da norma culta & educação idiomática deficiente \\
\hline ideal de perfeição & linguagem mutilada \\
\hline classes ilustradas & classes que vivem à margem da \\
& sociedade \\
\hline
\end{tabular}

A noção de língua associada à noção de correção, remete-nos também à noção de normal; e a noção de incorreção nos remete à noção de anormal. Assim, os pares opositivos, destacados das sequências discursivas recortadas para análise, deixam entrever o sentido filiado às noções de correto e incorreto.

Segundo Leite (2008), essas dicotomias, como tradição $X$ modernidade, saber $X$ não-saber e outras congêneres, e a partir do nosso objeto de análise podemos incluir a dicotomia correto $X$ incorreto, geram o que a autora denomina intolerância linguística, pois é um fenômeno ruidoso, explícito e manifesta-se, necessariamente, por um discurso metalinguístico calcado em dicotomias. "[...] a intolerância gera discursos sobre a verdade (ou verdades) e, também, sobre a compatibilidade/incompatibilidade teórica ou prática de duas verdades que se contrapõem" (p. 21).

Podemos observar que os termos e expressões listados na coluna referente à noção de normal/norma/correto formam uma rede significativa em que os sentidos se imbricam e se complementam, como em conservadora, culto e classes ilustradas. Forma-se assim uma rede de sentidos.

Em relação aos termos que se relacionam às noções anormal/diferente/incorreto, podemos observar o mesmo funcionamento 
discursivo: há uma solidariedade e complementaridade de sentidos: delinquentes, ignorante, deficiente, por isso, à margem da sociedade. E por que não dizer: os que se enquadram em uma forma de língua que se assemelha ao que se descreve em tal coluna, estão à margem da língua, estão em uma posição limítrofe, mas, que ainda lhes garante a posição de ser/estar sujeito da/na língua?

De acordo com Bauman (2001), a capacidade de conviver com a diferença não é fácil de adquirir e não se faz sozinha. A incapacidade de enfrentar a pluralidade perpetua a tendência à homogeneidade e o esforço para eliminar a diferença, e quanto mais ameaçadora a diferença, maior a intensidade e ansiedade que ela gera. É o desconforto da diferença, enquanto constitutiva que seduz o analista do discurso. Ele persegue as pistas para compreender os processos.

\section{Considerações finais}

Considerando que o objeto de análise deste trabalho é uma gramática normativa, é inevitável questionar: por que se encontra o "diferente" no interior do mesmo, partindo do princípio de que a gramática normativa representa um projeto de unicidade?

Apesar de o diferente não ser o modelo de língua, não é possível excluí-lo da língua. Mesmo em um instrumento linguístico que objetive descrever/prescrever uma unicidade, o heterogêneo funciona, uma vez que o "diferente" é constitutivo da língua.

Petri (2004, p. 222), já numa releitura de Guimarães, explicita quê:

É por estar previsto este cruzamento de discursos que podemos observar a presença do diferente no interior do mesmo, numa alternância de efeitos de sentido determinada pela FD na qual se efetua a designação. Dessa forma, a designação vai receber sentido num determinado momento, numa determinada FD e, ao mesmo tempo, vai estar silenciando outros sentidos possíveis.

De acordo com a análise, os resultados indicam que, mesmo a gramática sendo normativa, há espaços em que o "diferente" emerge, escapa do controle prescritivo e as designações funcionam como uma metalinguagem e põem em funcionamento um discurso sobre a língua.

É interessante observar o quanto a predicação do diferente é de ordem pejorativa, em oposição franca e direta ao normativo que leva à perfeição positivista, mas essa discussão é só um começo, há muito ainda para ser explorado.

Eis que assim percebemos que estamos diante de línguas fluidas $\underline{5}$, e que já não se sustenta a ideia de uma língua imaginária, pois a evidência de língua imaginária nos remete à evidência de um falante também imaginário, o que não 
existe, e é a "inexistência material desse falante" (BISINOTO, 2009, p. 120) que "anula" a possibilidade de perfeição e totalidade de uma gramática, tomada como um projeto de unicidade, e que insiste em representar uma língua imaginária: a língua fluida vem à tona, mesmo que discretamente, pois conseguimos percebê-la no fio do discurso.

Petri (2007), ancorando seu dizer em Pêcheux, explicita que esse autor aponta caminhos para pensarmos o espaço teórico da gramática de uma forma que comporta a diferença, pois esse espaço já não pode ser visto como perfeitamente, completamente homogêneo.

Não resta dúvida sobre o empenho de gramáticos - em suas gramáticas na manutenção de um saber clássico sobre a língua, enquanto elemento essencial para o constante fortalecimento do Estado/Nação. A gramática é resultado de um projeto de unicidade/unidade da língua, mas ela não é imune às características próprias da língua que comporta o mesmo e o diferente. É por compreendermos este movimento que discutimos a gramática enquanto instrumento linguístico, ferramenta política e designação que passa a funcionar em diferentes campos do saber.

Para encerrar, arriscamo-nos a dizer, então, que o que existe é um projeto imaginário de unicidade, que é afetado pelo "diferente", mesmo sob o status de normativo. Ao analista é possível perseguir as pistas, explicitar os processos, lutar para que o diferente continue emergindo no fio dos discursos, pois é isso que faz do sujeito o que ele é: falante da língua (que está/não está na gramática) que se relaciona com a ideologia e que é atravessado pelo inconsciente.

\section{Referências}

BAUMAN, Z. 2001. Modernidade líquida. Rio de Janeiro: Jorge Zahar Ed.

BISINOTO, L. S. J. 2009. Migrações internas, norma e ensino da língua portuguesa. Campinas: Editora RG.

CAMARA JÚNIOR, J. M. 1986. Dicionário de Linguística e Gramática: referente à língua portuguesa. Petrópolis, Vozes.

CANGuilheM, G. 2002. O normal e o patológico. Rio de Janeiro: Forense Universitária.

COURTINE, J. 2006. Metamorfoses do discurso político: as derivas da fala pública. São Carlos: Claraluz.

FÁVERO, L. L. 2006. As concepções linguísticas no Século XIX: a gramática no Brasil. Rio de Janeiro: Lucerna.

GUIMARÃES, E. 1995. Os Limites do Sentido: um estudo histórico e enunciativo da linguagem. Campinas, SP: Pontes. 
LEITE, M. Q. 2008. Preconceito e intolerância na linguagem. São Paulo: Contexto.

ORLANDI, E. P. 1987. A linguagem e seu funcionamento: as formas do discurso. Campinas, São Paulo: Pontes.

. 1988. Política linguística na América Latina. Campinas - SP: Pontes.

. (Org.). 2007. Política linguística no Brasil. Campinas - SP: Pontes Editores.

. 2009. Língua brasileira e outras histórias: discurso sobre língua e ensino no Brasil. Campinas: Editora RG.

PETRI, V. 2004. Imaginário sobre o gaúcho no discurso literário: da representação do mito em Contos Gauchescos, de João Simões Lopes Neto, à desmitificação e m Porteira Fechada, de Cyro Martins. Tese (Doutorado em Letras). Universidade Federal do Rio Grande do Sul, Rio Grande do Sul. 322 p.

. 2007. Algumas reflexões sobre discursividade, gramática e sintaxe. In: Michel Pêcheux e Análise do Discurso: uma relação de nunca acabar. São Carlos: Claraluz.

ROCHA LIMA, C. H. da. 1991. Gramática Normativa da Língua Portuguesa. 31. Ed. Rio de Janeiro, José Olympio.

SANTOS, B. da S. 2006. Gramática do tempo: para uma nova cultura política. Porto, Portugal: Afrontamento.

VIRNO, P. Gramática da Multidão. Para uma Análise das Formas de Vida Contemporâneas. Trad. de Leonardo Retamoso Palma. Santa Maria, RS. 2003.

Disponível em: < http://br.geocities.com/autoconvocad/gramatica da multidao.html>Acesso em: 30 mai. 2009.

1 Uma primeira versão deste texto foi apresentada no Grupo Temático Língua, sujeito e história, do VIII Encontro do CELSUL/RS, em outubro de 2008.

$\underline{2}$ Caracterizamos o processo de designação de acordo com Guimarães (1995, p. 74), o qual afirma que "a relação de designação é uma relação instável entre a linguagem e o objeto, pois o cruzamento de discursos não é estável, é ao contrário, exposta à diferença". Quando se designa, um sentido é instaurado e, como consequência, apagam-se outros possíveis sentidos, muito embora estes outros sentidos possam sempre retornar, o que depende das alterações de condições de produção, das tomadas de posição dos sujeitos, etc..

$\underline{3}$ Psicol. USP v.15 n.1-2 São Paulo jan./jun. 2004. Disponível em: <http://www.scielo.br/scielo.php? script $=$ sci arttext\&pid=S0103-65642004000100024\&lng =pt\&nrm=iso\&tlng=pt\#tx01>. Acesso em: 30 mai. 2009.

4 Esta discussão consta em um artigo intitulado "Georges Canguilhem na e pela História das Ideias Linguísticas", constitutivo do livro Memória e m Terceira Pessoa, organizado por Verli Petri e Amanda Scherer, no prelo.

$\underline{5}$ Aqui fazemos referência às noções de língua fluida e língua imaginária conforme as define Orlandi 
(1988; 2009). 